\title{
Anticuerpos contra la cardiolipina en glomerulonefritis postestreptocócica concurrente con anemia hemolítica autoinmunitaria: a propósito de un caso
} Anticardiolipin antibodies in concurrent poststreptococcal glomerulonephritis

Dra. Ying-liang Gong ${ }^{a}$ y Dr. Yu-feng $\mathrm{Li}^{a}$

\section{RESUMEN}

En este artículo, presentamos el caso de una paciente con glomerulonefritis aguda postestreptocócica (GNAPE) y anemia hemolítica autoinmunitaria (AHAI). Además de los signos típicos de la GNAPE, la paciente tuvo un resultado positivo en la prueba de antiglobulina directa y anticuerpos contra la cardiolipina sin que presentara las manifestaciones clínicas típicas del síndrome antifosfolipídico. Este caso genera dudas respecto de la relación entre el estreptococo y el desarrollo de anemia hemolítica autoinmunitaria en los niños. Este caso destaca la posibilidad de que las infecciones estreptocócicas de nuestra paciente podrían haber causado la anemia, ya sea en el contexto de anticuerpos antifosfolipídicos preexistentes o por haber desencadenado el desarrollo de anticuerpos patogénicos, queluego lleva a la presentación clínica dehemólisis. Se presume que, en la paciente, los anticuerpos contra la cardiolipina inducidos por la infección estreptocócica podrían tener una función directa en la presentación clínica de AHAI.

Palabras clave: niño, glomerulonefritis, anemia hemolítica autoinmunitaria, anticuerpos contra la cardiolipina.

http:/ / dx.doi.org/10.5546/aap.2018.e288

Texto completo en inglés:

http: / / dx.doi.org/10.5546/ aap.2018.eng.e288

Cómo citar: Gong Y, Li Y. Anticuerpos contra la cardiolipina en glomerulonefritis postestreptocócica concurrente con anemia hemolítica autoinmunitaria: a propósito de un caso. Arch Argent Pediatr 2018;116(2):e288-e291.

a. Departamento de Nefrología Pediátrica, Hospital Xinhua afiliado a la Facultad de Medicina de la Universidad de Shanghái Jiao Tong, Shanghái, China.

Correspondencia:

Dra. Ying-liang Gong: elainegongcn@outlook.com

Financiamiento: Ninguno.

Conflicto de intereses: Ninguno que declarar.

Recibido: 25-4-2017

Aceptado: 19-9-2017

\section{INTRODUCCIÓN}

La glomerulonefritis postestreptocócica es la causa más frecuente de glomerulonefritis en la niñez. ${ }^{1}$ En casos aislados, los pacientes podrían presentar una forma de rápida evolución o anemia, hipertensión y disfunción renal en el seguimiento a largo plazo. Sin embargo, la anemia grave no es frecuente en los pacientes con glomerulonefritis aguda postestreptocócica (GNAPE) y no se explica adecuadamente en algunos pacientes.

Los anticuerpos contra la cardiolipina pertenecen a la clase de los anticuerpos antifosfolipídicos y parecen estar relacionados con los procesos autoinmunitarios, entre otros, el síndrome antifosfolípidico y el lupus eritematoso sistémico. Se los describió en casos aislados de GNAPE. Aún no fue posible establecer su relevancia en las nefropatías. En este artículo, presentamos el caso de una niña con síndrome nefrótico, anemia hemolítica autoinmunitaria (AHAI) grave y anticuerpos contra la cardiolipina. Nunca antes se describió tal asociación y creemos que los anticuerpos contra la cardiolipina podrían ser más frecuentes en los pacientes con GNAPE de lo que se considera actualmente.

\section{A PROPÓSITO DE UN CASO}

Una niña de 10 años tuvo, durante 2 días, palidez, anorexia, fatiga y orina de color ámbar tras una enfermedad sin fiebre con faringitis (tratada con azitromicina durante 3 días). Se presentó en el Hospital Xinhua de Shanghái y se la hospitalizó en el servicio de nefrología ese mismo día.

Negó cualquier antecedente de hematomas sin explicación, sangre en las heces o menstruación anormal. Sus antecedentes médicos no presentaban particularidades. No presentaba anemia drepanocítica ni antecedentes indicativos de talasemia. Los signos vitales eran normales y la presión arterial era de 116/82 $\mathrm{mmHg}\left(\mathrm{P}_{95}\right)$. El examen físico reveló una paciente pálida, 
de contextura débil, con ojos hundidos, sin otras características relevantes. En la Tabla 1 se presentan los hallazgos clínicos y de laboratorio principales de la paciente durante la hospitalización.

A modo de resumen, se observó que tenía anemia normocrómica grave $(5,6 \mathrm{mg} / \mathrm{dl}$, intervalo de referencia: $11-15 \mathrm{mg} / \mathrm{dl}$ ), hematuria y proteinuria, hipocomplementemia y valor elevado de antiestreptolisina $\mathrm{O}$. La prueba de antiglobulina directa fue positiva con anti-C3. Los anticuerpos antinucleares y los anticuerpos anti-ADN bicatenario fueron negativos. Se le administraron antibióticos y tratamientos sintomáticos, por ejemplo, una transfusión de sangre. El tercer día de tratamiento se agregó metilprednisolona en una dosis de $2 \mathrm{mg}$ por kilogramo por vía intravenosa para la AHAI.

Sin embargo, a los cinco días de hospitalización, la concentración de hemoglobina volvió a la normalidad pero presentó oliguria y edema periorbitario y maleolar. La presión arterial era de $130 / 84 \mathrm{mmHg}\left(>\mathrm{P}_{99}\right)$ al momento de la aparición del edema. En los análisis de laboratorio adicionales se detectaron hipoalbuminemia, colesterol elevado y anticuerpos IgM contra la cardiolipina. En la ecografía se observó efusión pleural unilateral leve. Por motivos diagnósticos o pronósticos, se realizó una biopsia renal. En la microscopía óptica (Figura 1) de la biopsia renal se observó hipercelularidad, incluidas células mesangiales y endoteliales proliferativas e infiltrado leve de leucocitos mononucleares. De los 46 glomérulos, ninguno tenía formación semilunar. En la microscopía por inmunofluorescencia se observó depósito prominente de C3 junto al mesangio; la IgG y la IgA se tiñeron junto a la pared capilar. En la microscopía electrónica se identificaron numerosos depósitos densos en el espacio subepitelial de la membrana basal glomerular. La histología era compatible con glomerulonefritis postinfecciosa.

La concentración de hemoglobina se estabilizó en $12,0 \mathrm{~g} / \mathrm{L}$ tras ocho días de hospitalización. Posteriormente, la prueba de antiglobulina directa fue negativa y la concentración del complemento C3 se normalizó ocho semanas después de la hospitalización. En los dos años

Figura 1. Microscopía óptica de biopsia renal

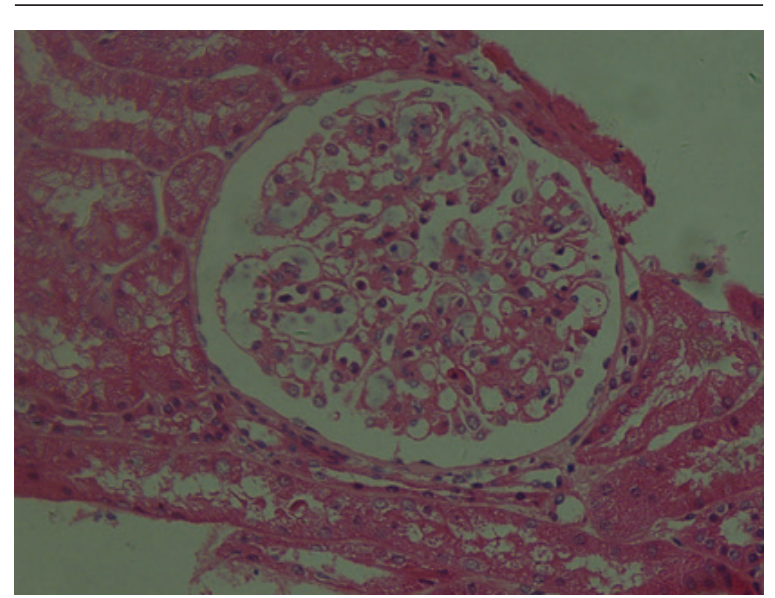

Infiltrado inflamatorio difuso e hipercelularidad mesangial (tinción con hematoxilina y eosina: aumento de 200x el original).

TABLA 1. Resultados principales de laboratorio tras la hospitalización

\begin{tabular}{|c|c|c|c|c|c|}
\hline & $\begin{array}{c}\text { Hemoglobina } \\
(\mathrm{g} / \mathrm{l})\end{array}$ & $\begin{array}{c}\text { Recuento de } \\
\text { reticulocitos }(\%)\end{array}$ & $\begin{array}{c}\text { Anticuerpos contra la } \\
\text { cardiolipina (IgM) }\end{array}$ & $\begin{array}{c}\text { Complemento } \\
\text { C3 }(\mathrm{g} / \mathrm{L}) \\
\end{array}$ & $\begin{array}{c}\text { Complemento } \\
\mathrm{C} 4(\mathrm{~g} / \mathrm{L}) \\
\end{array}$ \\
\hline \multicolumn{2}{|c|}{ Intervalo de referencia110-150 } & $0,5-1,5$ & negative & $0,9-1,8$ & $0,1-0,4$ \\
\hline Inicial & 56 & 5,25 & + & 0,04 & 0,18 \\
\hline Día 5 & 89 & / & / & / & / \\
\hline Semana 8 & 134 & 1,3 & / & 0,87 & 0,22 \\
\hline Mes 4 & 117 & l & + & 1,49 & 0,3 \\
\hline Mes 6 & 135 & l & / & l & / \\
\hline Mes 9 & 123 & 1,55 & \pm & 1,48 & 0,27 \\
\hline Mes 12 & 134 & / & \pm & 1,45 & 0,25 \\
\hline Mes 24 & 120 & / & / & / & / \\
\hline
\end{tabular}

La concentración de hemoglobina de la paciente era anormal al momento de la aparición y se estabilizó en 12,0 g/L tras el tratamiento durante ocho días. La concentración del complemento C3 era normal a las ocho semanas después de la hospitalización. Los anticuerpos contra la cardiolipina siguieron siendo positivos en el seguimiento a un año. 
posteriores al alta, la paciente siguió teniendo resultados positivos para los anticuerpos contra la cardiolipina pero sin signos de fiebre prolongada, trombocitopenia ni otros síntomas de síndrome antifosfolipídico o lupus eritematoso sistémico.

\section{DISCUSIÓN}

En este artículo, describimos a una niña con una constelación de signos y síntomas de anemia grave, síndrome nefrótico, evidencia serológica de infección estreptocócica reciente y disminución de la concentración sérica de C3, que se normalizó dentro de las ocho semanas. Durante el año de seguimiento, la paciente presentó anticuerpos IgM contra la cardiolipina positivos sin otras manifestaciones clínicas típicas de enfermedad trombótica. En la biopsia renal se observó la histología clásica de la glomerulonefritis postinfecciosa. El cuadro clínico era típico de GNAPE.

Los anticuerpos contra la cardiolipina pertenecen a la clase de los anticuerpos antifosfolipídicos y parecen estar relacionados con los procesos autoinmunitarios, entre otros, el síndrome antifosfolípidico y el lupus eritematoso sistémico. Se publicaron informes de anticuerpos antifosfolipídicos con glomerulonefritis postinfecciosa sin complicaciones. ${ }^{2,3}$ Hasta el momento no se había notificado otro caso como este de anticuerpos IgM contra la cardiolipina en un paciente con GNAPE complicada por AHAI. Sorpresivamente, es muy frecuente la presencia de anticuerpos contra la cardiolipina durante el período agudo y la convalecencia de la GNAPE, ${ }^{2}$ y se observó una incidencia del $44 \%$ de valores de anticuerpos IgM contra la cardiolipina anormales. Incluso entre los niños sanos, hasta el 25\% mostraron resultados positivos para los anticuerpos contra la cardiolipina. ${ }^{4}$ Se cree que los anticuerpos contra la cardiolipina aparecen en respuesta a muchas infecciones agudas, en especial durante la niñez. ${ }^{5}$ En una revisión, el $20 \%$ de los pacientes con VHC, el 49,75\% de los pacientes con VIH y el 25\% de aquellos con VHB y otras infecciones bacterianas, como infección estreptocócica, tenían una concentración sérica elevada de anticuerpos contra la cardiolipina. Worden y su equipo inyectaron una sonda de anticuerpos contra la proteína $\mathrm{M}$ del estreptococo mAb10F5 en ratas y estudiaron la presencia de anticuerpos antifosfolipídicos. ${ }^{6}$ Los resultados indicaron un aumento significativo de los anticuerpos antifosfolipídicos dos semanas después de la inyección, lo que demuestra que el estreptococo es causante de la generación de estos anticuerpos. Esta evidencia destaca la posibilidad de que la infección estreptocócica de nuestra paciente podría haber desencadenado el desarrollo de anticuerpos IgM contra la cardiolipina.

No es la primera vez que se detecta AHAI grave, como el caso que informamos, en pacientes con GNAPE. Larry y col., describieron tres casos similares, dos de los cuales tenían crioanticuerpos anti-I. ${ }^{7}$ Un niño de 10 años tenía insuficiencia renal anúrica y anemia hemolítica grave. Su valor elevado de antiestreptolisina $\mathrm{O}$ y la biopsia renal coincidían con GNAPE. ${ }^{8}$ La gravedad de la anemia no podía explicarse fácilmente por la hemodilución de la GNAPE. Los autores informaron que el $90 \%$ de los pacientes con GNAPE tenían anemia pero raramente la hemodilución era la única explicación. ${ }^{9}$ Se sabía poco sobre el mecanismo patogénico subyacente de la AHAI en los pacientes con GNAPE.

Según cierta evidencia, los anticuerpos contra la cardiolipina podrían tener una función directa en la patogenia de la anemia hemolítica en ciertas enfermedades. Sthoeger y col., observaron que los anticuerpos contra la cardiolipina funcionan como autoanticuerpos antieritrocitarios en el proceso de la AHAI en algunos pacientes con lupus eritematoso sistémico. ${ }^{10}$ Arvieux y col. informaron evidencia que indicaba que los anticuerpos IgG e IgM antifosfolipídicos causaban anemia hemolítica en un paciente con ciertas características clínicas de lupus eritematoso sistémico. ${ }^{11} \mathrm{Del}$ Papa y col. informaron la asociación de anemia hemolítica y anticuerpos IgG antifosfolipídicos en un paciente con síndrome antifosfolipídico primario. ${ }^{12}$ Jamie y su equipo estudiaron la presencia de anticuerpos antifosfolipídicos en suero mediante Elisa en pacientes con AHAI y sin hemólisis autoinmunitaria. Según los resultados, los anticuerpos antifosfolipídicos estaban presentes en una cantidad sustancial de pacientes con AHAI y esta respuesta no parecía secundaria a la hemólisis propiamente dicha. ${ }^{13}$ Se presume que, en nuestra paciente, los anticuerpos contra la cardiolipina inducidos por la infección estreptocócica podrían tener una función directa en la presentación clínica de AHAI.

Se ha informado una asociación entre los anticuerpos antifosfolipídicos y la trombosis glomerular en la nefropatía lúpica, y se han realizado diferentes interpretaciones sobre su función en la patogenia de la enfermedad 
renal. ${ }^{14}$ Todavía no se ha determinado si los anticuerpos antifosfolipídicos tienen una función patogénica en el contexto de la lesión renal en los pacientes con GNAPE. Se ha propuesto la hipótesis de que estos anticuerpos podrían potencialmente exacerbar la lesión tisular mediada por la inflamación. ${ }^{15}$ Sin embargo, Ardiles y col. no hallaron diferencias en el grado de lesión renal, en las anomalías glomerulares en la orina ni en la concentración de creatinina durante el seguimiento clínico de los pacientes con GNAPE que tenían resultados positivos para los anticuerpos contra la cardiolipina y aquellos con resultados negativos. ${ }^{2}$

Se considera que los anticuerpos contra la cardiolipina pueden estar asociados con un riesgo de trombosis si permanecen elevados. En ninguno de los casos publicados, y tampoco en nuestra paciente, se observó riesgo de enfermedad trombótica durante el seguimiento. Mediante este caso, se especuló que los anticuerpos contra la cardiolipina podrían ser más frecuentes en los pacientes con GNAPE de lo que se considera actualmente, y que la presencia de anticuerpos contra la cardiolipina en los pacientes con GNAPE podría ser un fenómeno inmunitario marginal desencadenado por la infección estreptocócica que carece de valor predictivo de la aparición posterior de otras enfermedades trombóticas.

\section{REFERENCIAS}

1. PanCG.Glomerulonephritis in childhood.Curr Opin Pediatr 1997;9(2):154-9.

2. Ardiles L, Ramirez P, Moya P, y col. Anticardiolipin Antibodies in Acute Poststreptococcal Glomerulonephritis and Streptococcal Impetigo. Nephron. 1999;83(1):47-52.

3. Leifer D, Butani L. Implications of antiphospholipid and antineutrophilic Cytoplasmic Antibodies in the Context of postinfectious glomerulonephritis. Case Rep Med. 2017;2017:9896210.

4. Siemens HJ, GutscheS, BrücknerS, et al. Antiphospholipid antibodies in children without and in adults with and without thrombophilia. Thromb Res. 2000;98(4):241-7.

5. Avcin T, ToplakN. Antiphospholipid antibodies in response to infection. Curr Rheumatol Rep. 2007;9(3):212-8.

6. Kelly-WordenM,ManningM,GebhardR, etal.Streptococcal M Protein Epitope 10F5 Generates Antiphospholipid Antibodies. Biophys J. 2016;110(3):79a-80a.

7. Greenbaum LA, Kerlin BA, Van Why S, et al. Concurrent poststreptococcal glomerulonephritis and autoimmune hemolytic anemia. Pediatr Nephrol. 2003;18(12):1301-3.

8. Cachat F, Dunsmore K, Tufro A. Concomitant anuric post-streptococcal glomerulonephritis and autoimmune hemolytic anemia. Eur J Pediatr. 2003;162(7-8):552-3.

9. Lau KK, Hastings MC, Delos Santos N, et al. A Child with Post-streptococcal Acute Glomerulonephritis Complicated by Coombs Positive Autoimmune Hemolytic Anemia. Internet J Radiol. 2007;4(1).

10. Sthoeger Z, Sthoeger D, Green L, et al. The role of anticardiolipin autoantibodies in the pathogenesis of autoimmune hemolytic anemia in systemic lupus erythematosus. J Rheumatol. 1993;20(12):2058-61.

11. Arvieux J, Schweizer B, Roussel B, et al. Autoimmune hemolytic anaemia due to anti-phospholipid antibodies. Vox Sang. 1991;61(3):190-5.

12. DelPapa N, Meroni PL, Barcellini W, etal. Antiphospholipid antibodies cross-reacting with erythrocyte membranes. A case report. Clin Exp Rheumatol. 1992;10(4):395-9.

13. Guzmán J, Cabral AR, Cabiedes J, y col. Antiphospholipid antibodies in patients with idiopathic autoimmune haemolytic anemia. Autoimmunity. 1994;18(1):51-6.

14. Frampton G, Hicks J, Cameron JS. Significance of antiphospholipid antibodies in patients with lupus nephritis. Kidney Int. 1991;39(6):1225-31.

15. Willis R, Gonzalez EB, Brasier AR. The journey of antiphospholipid antibodies from cellular activation to antphospholipid syndrome. Curr Rheumatol Rep. 2015;17(3):16. 